\title{
MEMS-FABRICATED ACCELEROMETERS WITH FEEDBACK COMPENSATION
}

\author{
Yonghwa Park*, Sangjun Park*, Byung-doo choi*, Hyoungho Ko*, Taeyong Song*, \\ Geunwon Lim*, Kwangho Yoo***, Sangmin Lee*, Sang Chul Lee***, Ahra Lee***, \\ Jaesang Lim**, and Dong-il "Dan" Cho****,+ \\ *School of Electrical Engineering and Computer Science, Seoul National University, \\ San 56-1, Shinlim-dong, Kwanak-gu, Seoul 151-742, Korea \\ **SML Electronics, Inc., Seoul, Korea
}

\begin{abstract}
This paper presents a feedback-controlled, MEMS-fabricated microaccelerometer. The microaccelerometer has received much commercial attraction, but its performance is generally limited. To improve the open-loop performance, a feedback controller is designed and experimentally evaluated. The feedback controller is applied to the $\mathrm{x} / \mathrm{y}$-axis microaccelerometer fabricated by sacrificial bulk micromachining (SBM) process. Even though the resolution of the closed-loop system is slightly worse than openloop system, the bandwidth, linearity, and bias stability are significantly improved. The noise equivalent resolution of open-loop system is $0.615 \mathrm{mg}$ and that of closed-loop system is $0.864 \mathrm{mg}$. The bandwidths of open-loop and closed-loop system are over 100 $\mathrm{Hz}$. The input range, non-linearity and bias stability are improved from $\pm 10 \mathrm{~g}$ to $\pm 18 \mathrm{~g}$, from $11.1 \% \mathrm{FSO}$ to $0.86 \% \mathrm{FSO}$, and from $0.221 \mathrm{mg}$ to $0.128 \mathrm{mg}$ by feedback control, respectively. Copyright (C) 2005 IFAC
\end{abstract}

Keywords: Acelerometers, Feedback control, Modelling, Simulation

\section{INTRODUCTION}

Micro-fabricated accelerometers have received much commercial attraction due to the small size, low power consumption, rigidity, and low cost (Song, 1977). However, because of the very small size, the open-loop performance is generally limited. To improve the open-loop performance, we design a feedback controller in this paper. The closed-loop system feeds the control signal from the sensed output signal back to the feedback control electrodes. This makes the displacement of the moving parts very small, and the bandwidth of the system is increased. Furthermore, because the displacement of the moving parts is controlled to be small, the linearity of the output signal can be improved.

\section{WORKING PRINCIPLE}

Figure 1 shows the $\mathrm{x} / \mathrm{y}$-axis microaccelerometer with feedback control electrodes. A quarter of sensing electrodes are used as feedback control electrode. The SBM-fabricated microaccelerometer has a $40 \mu \mathrm{m}$ of structural thickness and a $20 \mu \mathrm{m}$ of sacrificial gap. The SBM process has the added benefits of a large sacrificial gap when compared to conventional SOI process (Lee, et al., 1999; Lee, et al., 2000; Cho, et al., 2000).

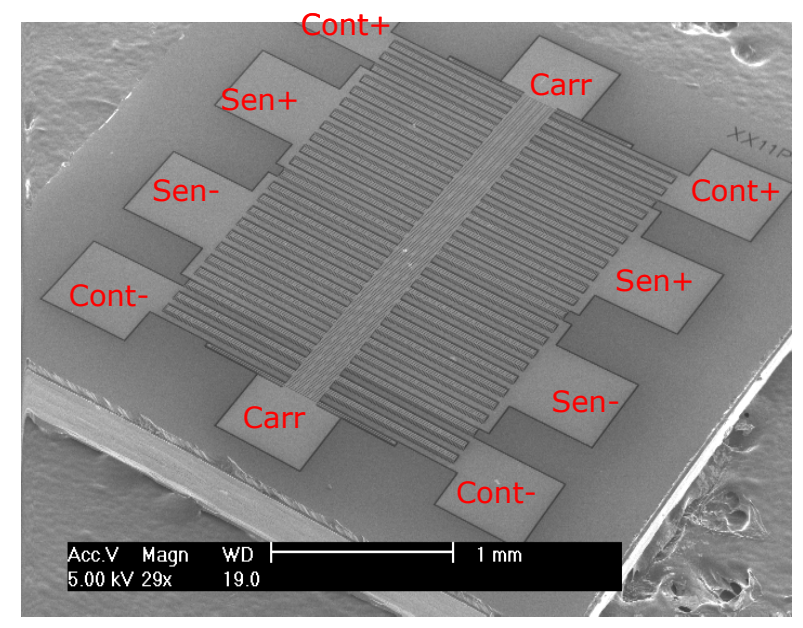

Fig. 1. Fabricated microaccelerometer.

\footnotetext{
${ }^{+}$Corresponding author, Phone: +82.2.880.8371, Fax: +82.2.877.9304, E-mail: dicho@asri.snu.ac.kr
} 
Figure 2 shows the schematics of microaccelerometer and readout circuit. The inertia force exerted by applied acceleration compels the proof mass to move, and this motion produces the capacitance change. The capacitance change is detected by a charge-to-voltage converter. After the high-pass filtering, the signal is demodulated using an analog multiplier. After low-pass filtering, the demodulated acceleration signal is obtained without the high frequency components.

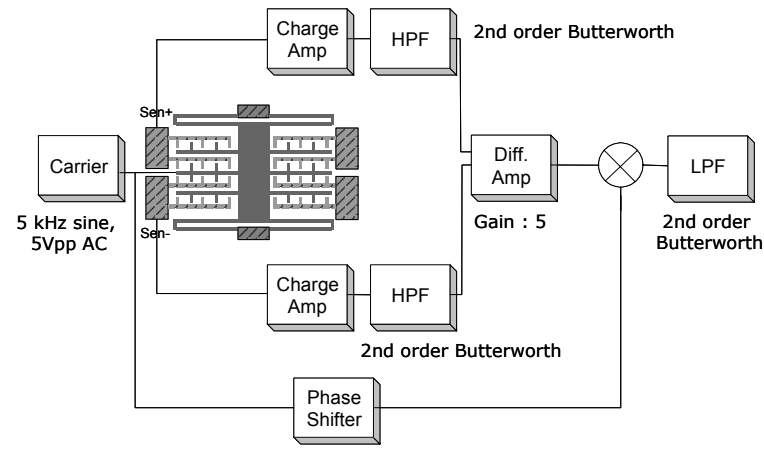

Fig. 2. Schematics of microaccelerometer and readout circuit

\section{DYNAMIC MODELLING}

\subsection{Microaccelerometer}

The microaccelerometer consists of proof mass, flexures, sensing combs, and control combs as shown in Figure 1. The dynamics of the microaccelerometer can be simply modeled as a mass-damper-spring system as showed in Figure 3. The equation of the sensing motion is given by

$$
m \ddot{x}+b \dot{x}+k x=m a
$$

where $\mathrm{m}, \mathrm{b}, \mathrm{k}$ are mass, damping, and spring coefficient of the sensing mode, respectively; $\mathrm{x}$ is displacement of the proof mass and a is an external acceleration.

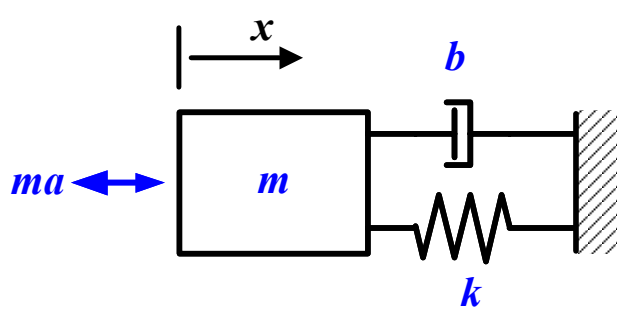

Fig. 3. Modelling of the microaccelerometer

The microaccelerometer has a structural thickness of $40 \mu \mathrm{m}$, a lateral gap between electrodes of $1.5 \mu \mathrm{m}$, and a spring length of $452 \mu \mathrm{m}$. The values of $\mathrm{m}, \mathrm{b}$, and $\mathrm{k}$ can be obtained from the structure of the microaccelerometer and the equations of relation between the resonant frequency, quality factor, and damping coefficient. The resonant frequency and quality factor are given by

$$
\begin{gathered}
\frac{f=\frac{1}{2 \pi} \sqrt{\frac{k}{m}}}{Q}=\frac{\mu A \beta}{\sqrt{m k}\left(\frac{\cosh 2 \beta d-\cos 2 \beta d}{\sinh 2 \beta d+\sin 2 \beta d}\right)}+ \\
\frac{\mu A_{c} \beta}{\sqrt{m k}\left(\frac{\cosh 2 \beta d_{c}-\cos 2 \beta d_{c}}{\sinh 2 \beta d_{c}+\sin 2 \beta d_{c}}\right)}+\frac{\mu t W^{3}}{d_{2}^{3} \sqrt{m k}}
\end{gathered}
$$

where $\mu, \beta, A, A_{c}, d, d_{c}, d_{2}, t$, and $W$ are absolute viscosity, momentum propagation velocity, area of plate, areas of inter-comb, sacrificial gap, lateral gap between combs, gap between structure and comb, structural thickness, and width of comb, respectively (Cho, et al., 1993). Also, damping coefficient is given by

$$
b=\frac{\sqrt{m k}}{Q} .
$$

The calculated mass, $\mathrm{m}$, is $122 \mu \mathrm{g}$. By ANSYS simulation, the first mode resonant frequency is $1 \mathrm{kHz}$. From Eq. (2), the value of $k$ is $4.82 \mathrm{~N} / \mathrm{m}$. From Eqs. (3) - (4), the value of b is $1.917 \times 10^{-5} \mathrm{~kg} / \mathrm{s}$. Therefore, from Eq. (1), the transfer function of the microaccelerometer $\mathrm{T}(\mathrm{s})$ becomes

$$
T(s)=\frac{X(s)}{F(s)}=\frac{8.2 \times 10^{6}}{s^{2}+157 s+3.95 \times 10^{7}} .
$$

The movement of the proof mass exerted by applied acceleration compels the areas of inter-comb to vary, and this variation produces the capacitance change. So, C/X gain, that is, the ratio of the capacitance change to the movement of the proof mass is given by

$$
C / X \text { Gain }=\frac{N_{1} \varepsilon t}{d_{c}}
$$

where $\mathrm{N}_{1}$ is number of combs for sensing and $\varepsilon$ is permittivity. The calculated $\mathrm{C} / \mathrm{X}$ gain is $1.013 \times 10^{-7} \mathrm{C} / \mathrm{m}$.

\subsection{Measurement Circuit}

The measurement circuit consists of the charge amplifier, the high-pass filter, the differential amplifier, the phase shifter, the analog multiplier, and the low-pass filter, which are shown in Figure 2. The output voltage of the charge amplifier $\mathrm{V}_{\mathrm{o}}(\mathrm{s})$ is given by

$$
V_{o}(s)=-\left(\frac{0.198 s}{s+2 \times 10^{4}}+\frac{2 \times 10^{12} s}{s+2 \times 10^{4}} C(s)\right) V_{\text {Carr }}(s)
$$

where $\mathrm{C}(\mathrm{s})$ is capacitance change and $\mathrm{V}_{\mathrm{Carr}}(\mathrm{s})$ is carrier signal. The transfer functions of the high-pass filter and the low-pass filter are given by

$$
T_{H}(s)=-\frac{s^{2}}{s^{2}+3.16 \times 10^{3} s+3.96 \times 10^{6}}
$$




$$
T_{L}(s)=\frac{2.07 \times 10^{15}}{\left(s^{2}+9091 s+4.55 \times 10^{7}\right)^{2}} .
$$

where $\mathrm{T}_{\mathrm{H}}(\mathrm{s})$ is a 2nd-order butterworth high-pass filter and $\mathrm{T}_{\mathrm{L}}(\mathrm{s})$ is two 2nd-order butterworth lowpass filter. Also, the gain of the differential amplifier is $5.27 \mathrm{~V} / \mathrm{V}$.

\section{CONTROLLER DESIGN}

Figure 4 shows the block diagram of the closedloop system. The closed-loop system feeds the control signal from the demodulated output signal back to the feedback control electrodes. From the relation of the input acceleration and the demodulated output signal, this plant $\mathrm{G}(\mathrm{s})$ can be modelled as a simple 2nd-order transfer function as follows;

$$
G(s)=\frac{1.455 \times 10^{13}}{s^{2}+157 s+3.95 \times 10^{7}} .
$$

If the output voltage of the controller is applied to the feedback control electrodes, the electrostatic force is exerted on the inter-combs. The F/V gain, that is, the ratio of the electrostatic force to the control output voltage is given by

$$
F / V \text { Gain }=\frac{2 N_{2} \varepsilon t V_{o f f}}{d_{c}}
$$

where $\mathrm{N}_{2}$ is number of combs for feedback and $\mathrm{V}_{\text {off }}$ is feedback offset voltage. The calculated $\mathrm{F} / \mathrm{V}$ gain is $4.87 \times 10^{-7} \mathrm{~N} / \mathrm{V}$.

The damping ratio of this plant is very small. So, the overshoot of this plant is very large and the settling time is very long. Figure 5 shows the step response of the open-loop system, when the input acceleration is $1 \mathrm{~g}$. The settling time is $49.5 \mathrm{~ms}$ and the modulated output signal is $0.44 \mathrm{~V}$.

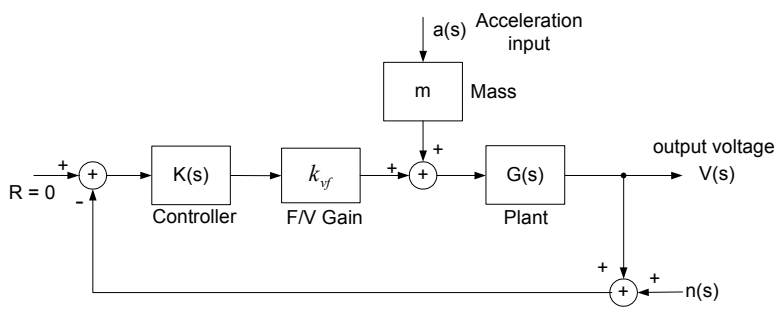

Fig. 4. Block diagram of the closed-loop system

If an external acceleration is applied to the accelerometer, the proof mass should quickly reach the position as much as the magnitude of acceleration. Then the accelerometer should be ready to receive some other external acceleration. So, the feedback controller $\mathrm{K}(\mathrm{s})$ is designed to reduce the settling time of this system and increase the damping ratio. The simplest controller that satisfies this condition is a PD controller. The feedback controller K(s) is given by

$$
K(s)=K_{P}\left(1+T_{D} s\right)
$$

where $K_{P}$ is the proportional feedback gain, and $T_{D}$ is the derivative rate.

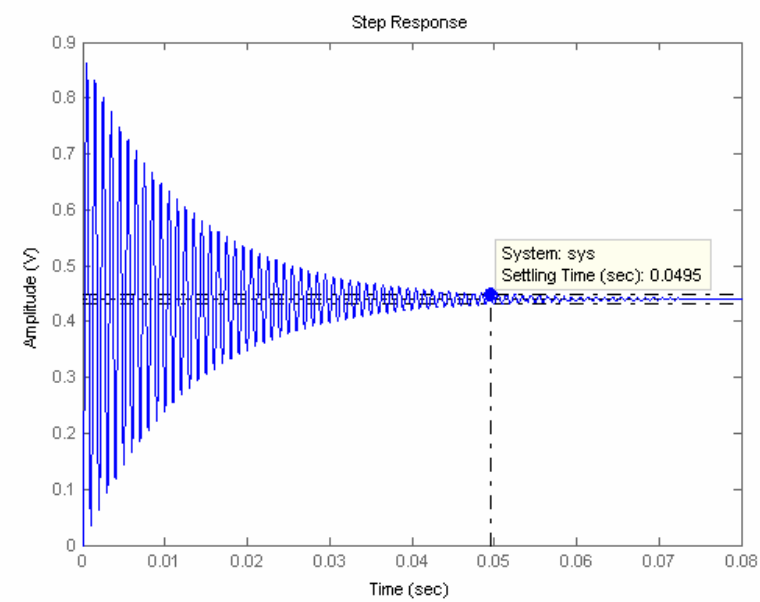

Fig. 5. Step response of the open-loop system.

First of all, the suitable value of $T_{D}$ is selected. When the value of $T_{D}$ is $0.001 \mathrm{sec}$, the value of $K_{P}$ can be easily selected using the root locus technique. If the value of $K_{P}$ is 1.4 , the damping ratio is 0.718 and the step response of the closed-loop system is obtained as shown in Figure 6. The settling time of the closed-loop system is reduced from $49.5 \mathrm{~ms}$ to $0.844 \mathrm{~ms}$, and the modulated output signal is decreased from $0.4 \mathrm{~V}$ to $0.352 \mathrm{~V}$, when compared to the open-loop system.

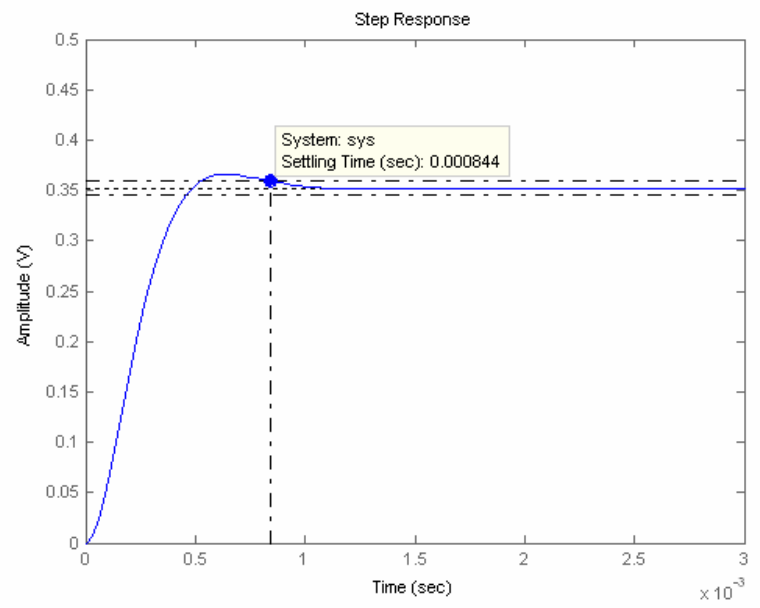

Fig. 6. Step response of the closed-loop system.

\section{SIMULATION RESULTS}

We use the MATLAB SIMULINK as the simulation program. Figure 7 shows the SIMULINK block diagram of the closed-loop system. With the input acceleration of $1 \mathrm{~g}$ at $40 \mathrm{~Hz}$, Figure 8 shows the frequency response of the modulated output signal. Because the average output signal is decreased, the noise equivalent input acceleration resolution of the closed-loop system gets worse from 0.273 $\mathrm{mg}$ to $0.332 \mathrm{mg}$, when compared to the open-loop system. But the noise floor of the closed-loop system is also decreased. The average output signal level and the noise floor of the open-loop system are $-17.1 \mathrm{~dB}$ and $-88.4 \mathrm{~dB}$, 
respectively, and the average output signal level and the noise floor of closed-loop system are $-21.0 \mathrm{~dB}$ and $-90.6 \mathrm{~dB}$, respectively.

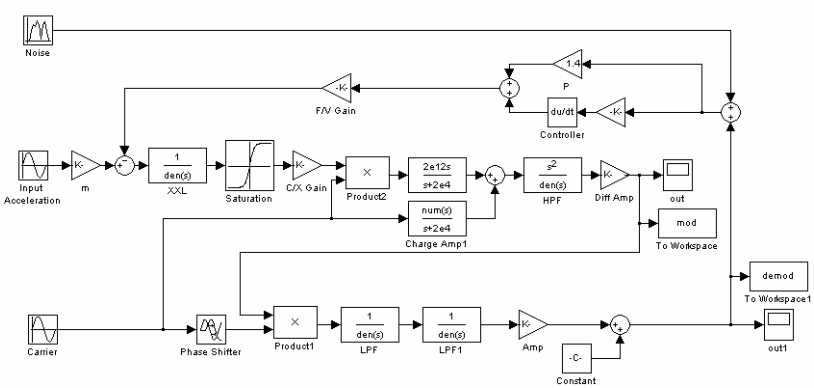

Fig. 7. SIMULINK block diagram of the closed-loop system

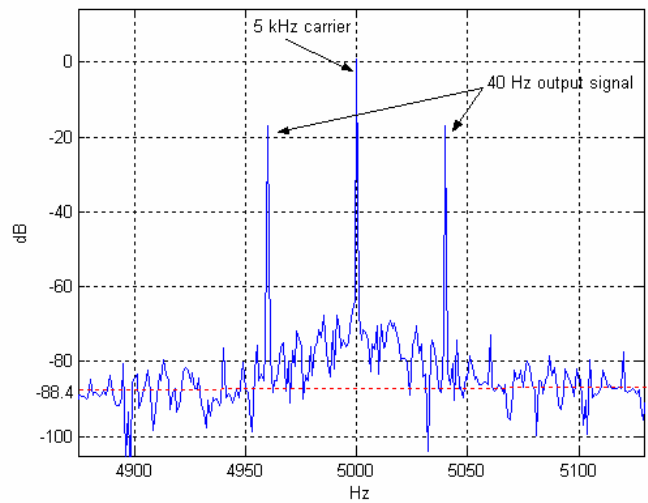

(a) Open-loop system

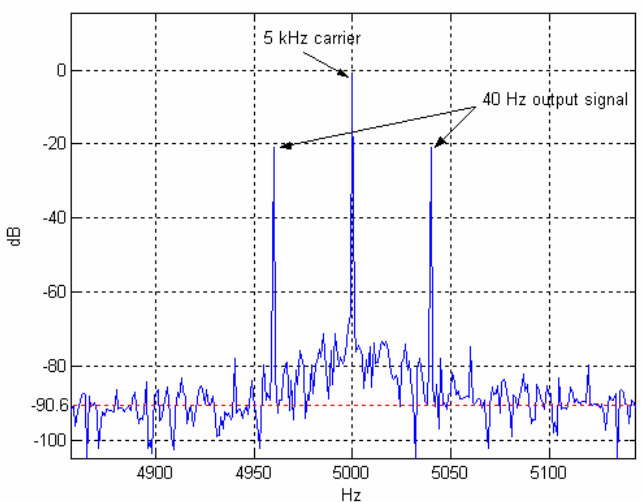

(b) Closed-loop system

Fig. 8. Frequency response of the modulated output signal at $40 \mathrm{~Hz}, 1 \mathrm{~g}$ input acceleration

Figure 9 shows the bode diagram of the demodulated output signal. This output signal is obtained by increasing the period of input acceleration. The bandwidth of the closed-loop system is improved from $500 \mathrm{~Hz}$ to $800 \mathrm{~Hz}$. Figure 10 shows the demodulated output signal when the magnitude of input acceleration varies. The scale factor of the closed-loop system is decreased to 0.35 $\mathrm{V} / \mathrm{g}$ from $0.41 \mathrm{~V} / \mathrm{g}$ of the open-loop system. The input range of the closed-loop system is improved from $\pm 10 \mathrm{~g}$ to $\pm 18 \mathrm{~g}$. Also, the non-linearity of the closed-loop system is improved from $11 \% \mathrm{FSO}$ to $0 \% \mathrm{FSO}$ in the $\pm 18 \mathrm{~g}$ range.

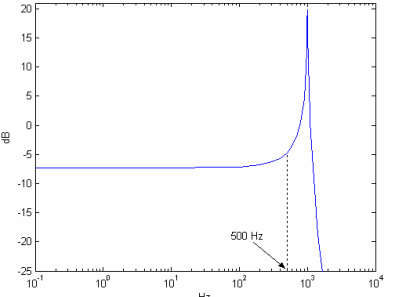

(a) Open-loop system

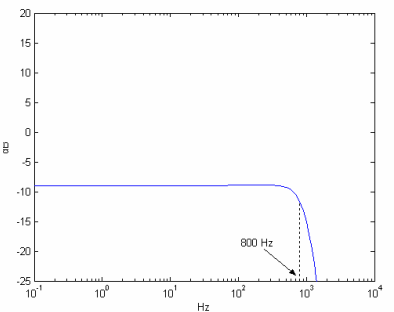

(b) Closed-loop system
Fig. 9. Bode diagram of the demodulated output signal

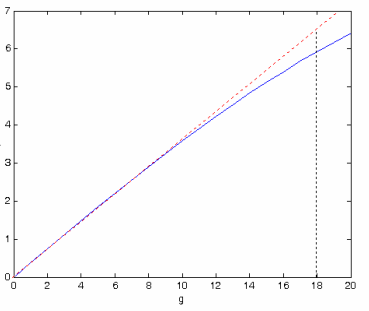

(a) Open-loop system

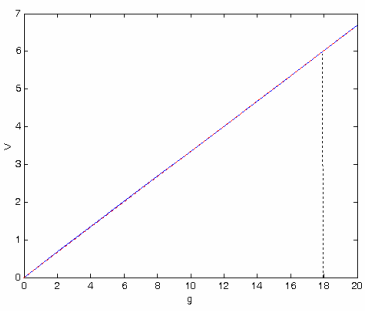

(b) Closed-loop system
Fig. 10. Linearity and input range of the output signal

\section{EXPERIMENTAL RESULTS}

Figure 11 shows the closed-loop implementation of the microaccelerometer. After a 5 volt peak-to-peak sinusoidal voltage without offset voltage is applied to the proof mass of the microaccelerometer, we measure the output voltage when an external acceleration is applied using the shaker table as shown in Figure 12.

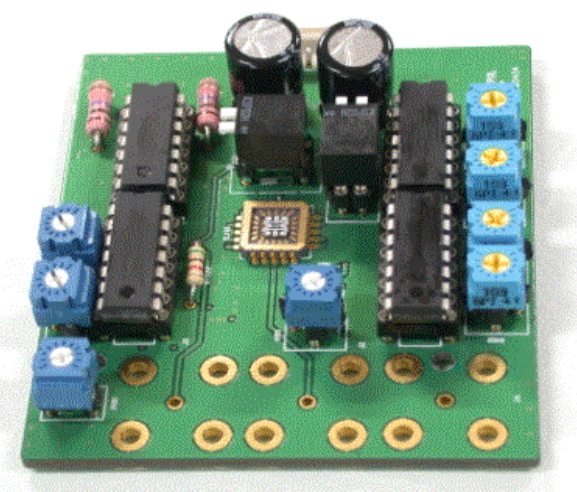

Fig.11. Closed-loop implementation of microaccelerometer

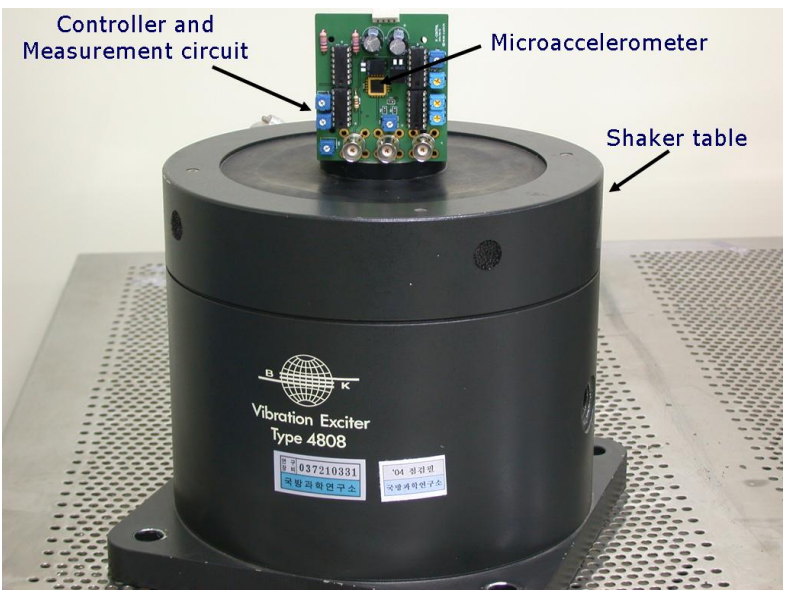

Fig. 12 Experimental setup using the shaker table 
Figure 13 shows the modulated output signal of the fabricated accelerometer when the input acceleration of $1 \mathrm{~g}$ at $40 \mathrm{~Hz}$ is applied. The noise equivalent input acceleration resolution, the average output signal level, and the noise floor of the closedloop system are all decreased such as the simulation result, when compared to the open-loop system. The noise equivalent input acceleration resolution of the closed-loop system gets worse from $0.615 \mathrm{mg}$ to $0.864 \mathrm{mg}$. The average output signal level and the noise floor of the open-loop system are $-17.19 \mathrm{~dB}$ and $-81.41 \mathrm{~dB}$, respectively, and the average output signal level and the noise floor of closed-loop system are $-21.85 \mathrm{~dB}$ and $-83.12 \mathrm{~dB}$, respectively. Because the noise floor of the measurement result is larger than the simulation result, the resolution of the measurement result becomes worse than the simulation result. The measurement circuit and the measurement environment should be improved to solve this noise problem.

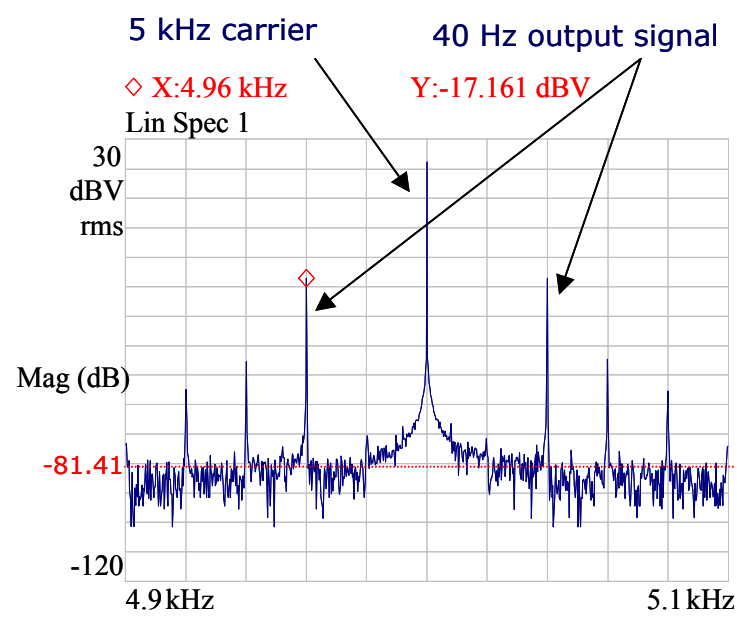

(a) Open-loop system

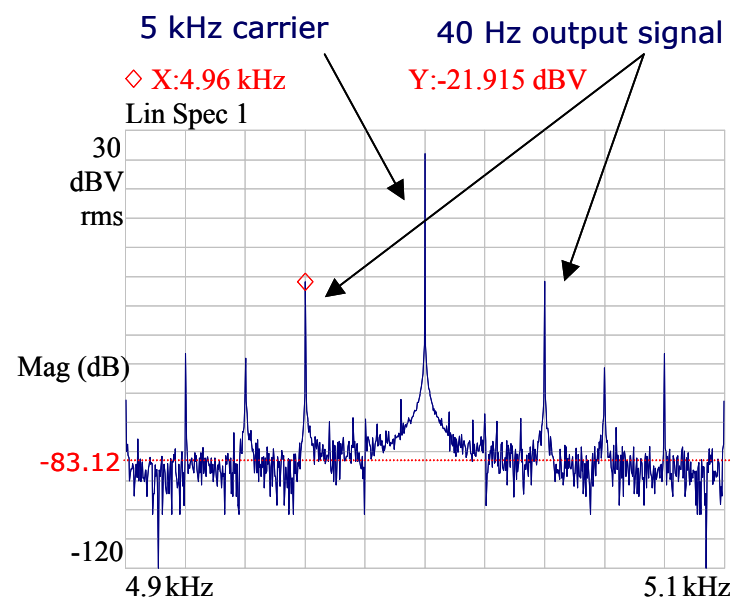

(b) Closed-loop system

Fig. 13. Frequency response of the modulated output signal at $40 \mathrm{~Hz}, 1 \mathrm{~g}$ input acceleration

Figure 14 shows the frequency response of the demodulation output signal. The frequency response of the open-loop and the closed-loop system are measured only up to the shaker table limit of $100 \mathrm{~Hz}$.
The bandwidth cannot be measured using the shaker table. Figure 15 shows the linearity of the output signal when the magnitude of input acceleration varies at $40 \mathrm{~Hz}$. We obtain the similar result with the simulation result. The scale factor of the closed-loop system is decreased to $0.376 \mathrm{~V} / \mathrm{g}$ from $0.406 \mathrm{~V} / \mathrm{g}$ of the open-loop system. The input range of the closed-loop system is improved from $\pm 10 \mathrm{~g}$ to $\pm 18 \mathrm{~g}$. Also the non-linearity of the closed-loop system is improved from $11.12 \% \mathrm{FSO}$ to $0.86 \% \mathrm{FSO}$ in the $\pm 18 \mathrm{~g}$ range. Finally, the bias stability tests are performed. Figure 16 shows the demodulated output signal without applied the input acceleration. The bias stability of the closed-loop system is improved from $0.221 \mathrm{mg}$ to $0.128 \mathrm{mg}$. The specifications are summarized in table 1.

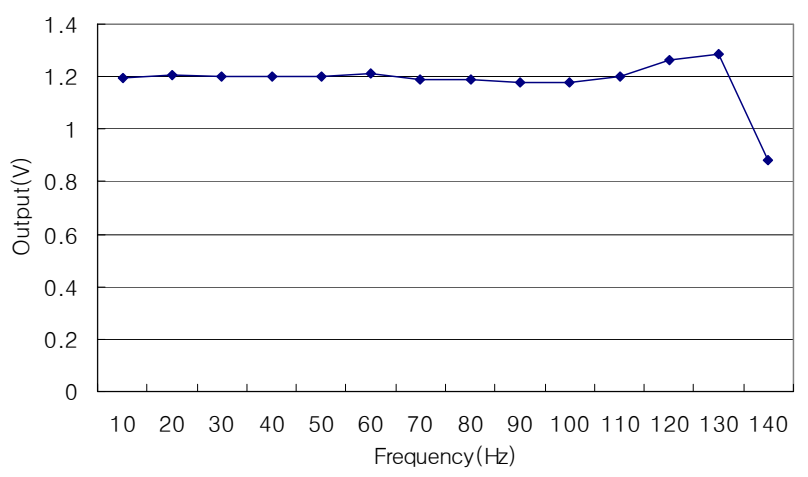

(a) Open-loop system

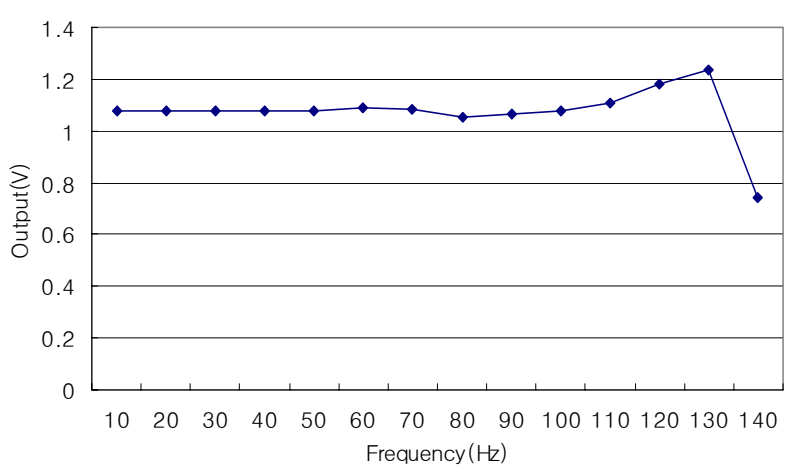

(b) Closed-loop system

Fig. 14. Frequency response of the demodulated output signal

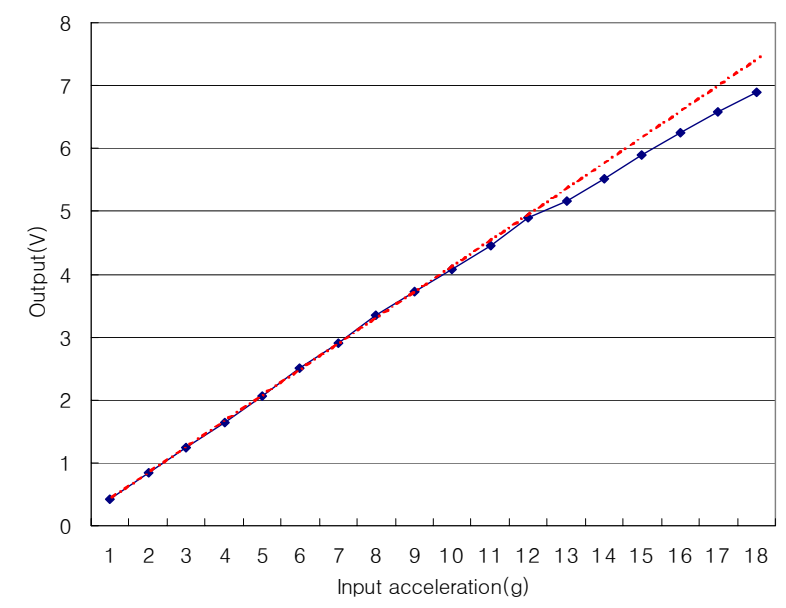

(a) Open-loop system 


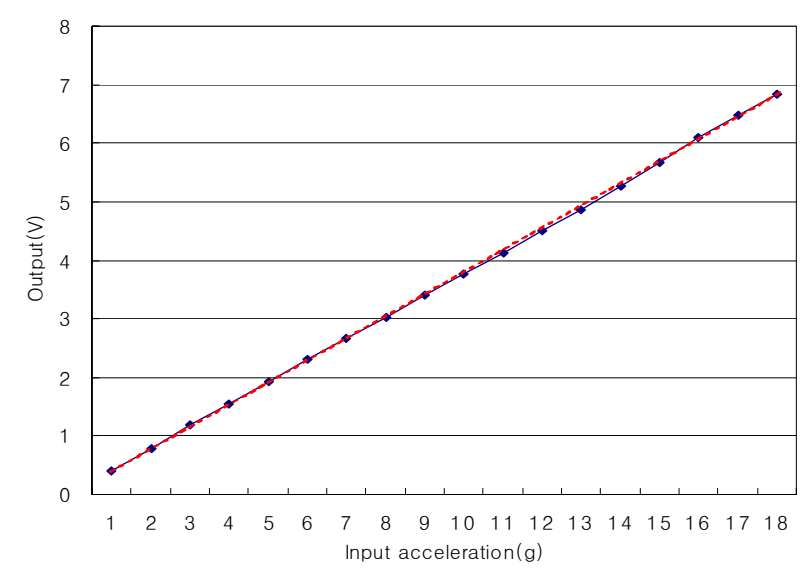

(b) Closed-loop system

Fig. 15. Linearity and input range at $40 \mathrm{~Hz}$

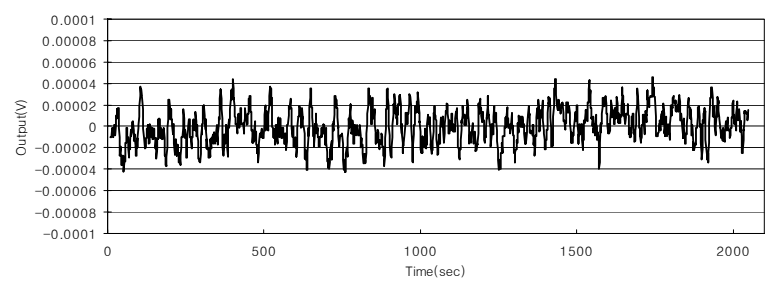

(a) Open-loop system

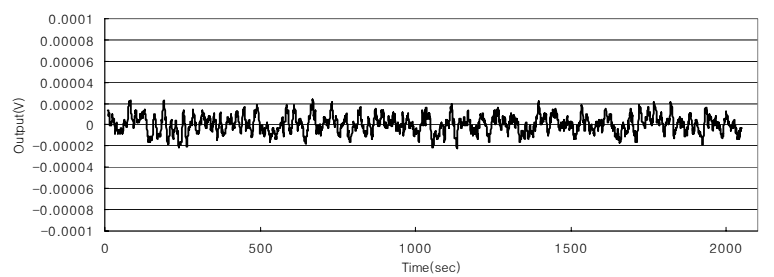

(b) Closed-loop system

Fig. 16. Bias stability of the demodulated output signal

Table 1 Performance summary of the system.

\begin{tabular}{|c|c|c|}
\hline & $\begin{array}{c}\text { Open-loop } \\
\text { system }\end{array}$ & $\begin{array}{c}\text { Closed-loop } \\
\text { system }\end{array}$ \\
\hline Resolution & $0.615 \mathrm{mg}$ & $0.864 \mathrm{mg}$ \\
\hline Noise floor & $-81.41 \mathrm{~dB}$ & $-83.12 \mathrm{~dB}$ \\
\hline Bandwidth & $>100 \mathrm{~Hz}$ & $>100 \mathrm{~Hz}$ \\
\hline Input range & $\pm 10 \mathrm{~g}$ & $\pm 18 \mathrm{~g}$ \\
\hline $\begin{array}{c}\text { Non-linearity } \\
\text { (in 18 g range) }\end{array}$ & $11.12 \% \mathrm{FSO}$ & $0.86 \% \mathrm{FSO}$ \\
\hline Bias stability & $0.221 \mathrm{mg}$ & $0.128 \mathrm{mg}$ \\
\hline
\end{tabular}

\section{CONCLUSION}

In this paper, a simple PD controller is designed for a MEMS microaccelerometer. Using this simple controller, the performances of the microaccelerometer such as the bandwidth, linearity, and bias stability are improved by feeding the control signal from the sensed output signal back to the sensing-comb electrodes. The most dramatic improvements are in the range and linearity. The input range is improved from $\pm 10 \mathrm{~g}$ to $\pm 18 \mathrm{~g}$, and the nonlinearity is improved from $11.12 \% \mathrm{FSO}$ to $0.86 \% \mathrm{FSO}$. The resolution is slightly degraded from $0.615 \mathrm{mg}$ to 0.864 $\mathrm{mg}$, which is attributed to the additional electrodes. However, the more important measure relating to resolution is bias stability, and the bias stability is improved from $0.221 \mathrm{mg}$ to $0.128 \mathrm{mg}$. This bias stability improvement is achieved because the closed-loop system can maintain the proof mass at the zero position better than the open-loop system in the absence of external accelerations.

\section{ACKNOWLEDGMENTS}

This research, under the contract project code A11000400-0058, has been supported by the Intelligent Robot Sensors sponsored by the Ministry of Information and Communication Republic of Korea.

\section{REFERENCES}

Cho, Y. H., B. M. Kwak, A. P. Pisano, and R. T. Howe (1993). Viscous energy dissipation in laterally oscillating planar microstructures: A theoretical and experimental study. Proc. IEEE Workshop on Microelectro-mech. Sys., pp. 93-99.

Song, Cimoo. (1997). Commercial Vision of Silicon Based Inertial Sensors. Proceedings of Transducers '97, vol. 2, pp. 839-842.

Lee, S., S. Park, and D. Cho (1999). The Surface/Bulk Micromachining (SBM) process: a new method for fabricating released microelectromechanical systems in single crystal silicon. IEEE/ASME Journal of Microelectromechanical Systems, vol. 8, no. 4, pp. 409-416.

Lee, S., S. Park, J. Kim, S. Yi, and D. Cho (2000). Surface/Bulk Micromachined Single-crystalline Silicon Micro-gyroscope. IEEE/ASME Journal of Microelectromechanical Systems, vol. 9, no. 4, pp. 557-567.

Cho, D., S. Lee, and S. Park (2000). Surface/Bulk Micromachined High Performance Silicon Microgyroscope. 2000 Solid-state Sensor and Actuator Workshop (Hilton Head). 